\title{
INSTALLING AND OPERATING FEGTEM'S
}

\section{C.J.D. HETHERINGTON* ${ }^{*}$ A.G. CULLIS*, S. WALKER*, J. TURNER ${ }^{* *}$, E.C. NELSON**, M.A. O'KEEFE*}

*Sheffield University, Department of Electronic and Electrical Engineering, Mappin Street, Sheffield, S1 3JD, UK

** Lawrence Berkeley National Laboratory, National Center for Electron Microscopy, MS 72-150, Berkeley, CA 94720

\section{DISCLAIMER}

This document was prepared as an account of work sponsored by the United States Government. While this document is believed to contain correct information, neither the United States Government nor any agency thereof, nor The Regents of the University of California, nor any of their employees, makes any warranty, express or implied, or assumes any legal responsibility for the accuracy, completeness, or usefulness of any information, apparatus, product, or process disclosed, or represents that its use would not infringe privately owned rights. Reference herein to any specific commercial product, process, or service by its trade name, trademark, manufacturer, or otherwise, does not necessarily constitute or imply its endorsement, recommendation, or favoring by the United States Government or any agency thereof, or The Regents of the University of California. The views and opinions of authors expressed herein do not necessarily state or reflect those of the United States Government or any agency thereof, or The Regents of the University of California.

Ernest Orlando Lawrence Berkeley National Laboratory is an equal opportunity employer.

Ernest Orlando Lawrence Berkeley National Laboratory - LBNL-49175 


\title{
INSTALLING AND OPERATING FEGTEM'S
}

\author{
C.J.D. HETHERINGTON*, A.G. CULLIS*, S. WALKER*, J. TURNER**, E.C. NELSON**, M.A. O’KEEFE* \\ *Sheffield University, Department of Electronic and Electrical Engineering, Mappin Street, Sheffield, S1 3JD, UK \\ ** Lawrence Berkeley National Laboratory, National Center for Electron Microscopy, MS 72-150, Berkeley, CA 94720
}

\section{ABSTRACT}

The latest transmission electron microscopes with field emission guns and imaging filters now provide much of the microanalysis and imaging necessary in applications such as ULSI device development. The installation and operating environment of the instruments are critical to their successful operation. Information from two such installations is presented here, one in a purpose built facility and the other in an existing building. The levels of ground vibration, acoustic noise, stray electromagnetic fields and airflow and temperature are presented, and the measures to achieve them are discussed. The physical layout of an installation is also shown.

\section{INTRODUCTION}

The new generation of FEGTEM's (field emission gun transmission electron microscopes) has the potential to fulfil many of the imaging and analysis requirements in ULSI (ultra-large scale integration) development. This potential can be realised, however, only if the installation - the microscope room and its environment - meets increasingly tight specifications. Similarly, the growing number of microscope accessories and peripherals - imaging filters, field cancellation systems, plasma cleaners, network connections and so on - requires careful management for seamless and reliable operation of the facility as a whole.

From time to time, it has been thought appropriate to document the details of the installation and the volume by Anderson [1] written in 1975 has long been the standard reference for designing a microscope laboratory. Since then developments in the instrumentation have lead to tighter specifications and additional requirements for the laboratory. For example, the image resolution of the current microscopes,

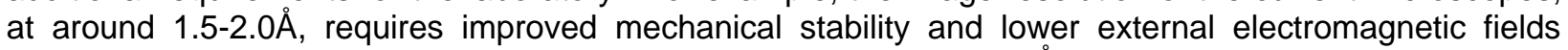
compared to earlier machines having resolutions in the range 3.0-4.0 $\AA 2,3]$. Mapping elements through an imaging filter requires multiple exposures of the same area of specimen; hence, specimens must not drift over periods of several minutes and this places strict limits on room temperature variation.

In the past, it had become notorious that the peak performance of microscopes was achievable only late at night when external disturbances were lowest. Nowadays, safe working practice at many sites discourages experimental work except during regular hours, and at other sites, peak performance is required around the clock. In both circumstances, it is clearly necessary to isolate the machine from external influences.

Observations and experiences are collated here from recent FEGTEM installations. One is a Philips CM300FEG located in purpose-built accommodation in Berkeley [4] and the other a JEOL 2010F located in refitted accommodation in an eighty-five year old building in Sheffield. Further comments derive from installations at other sites, including the department of Materials Science and Engineering in Cambridge, UK.

\section{GROUND VIBRATIONS}

Vibrations in a floor supporting the microscope may enter through two routes. The first route is via the bedrock on which the building sits. One source can be microseisms - ground vibrations caused by the action of wind on hills, waves on seashores or even the movement of glaciers. These microseisms play the rôle of "background noise" in seismology readings and those at the Berkeley site track the storm activity of the Northern California coast. Other sources of vibrations in the bedrock are local road or rail traffic, or machinery in nearby heavy industry (still a factor in Sheffield). The critical frequencies for microscopes are the $1-5 \mathrm{~Hz}$ range. 
The microscope foundation at both sites is a large (around $1 \mathrm{~m}$ thick and $4 \mathrm{~m}$ square) concrete base weighing around $20,000-35,000 \mathrm{~kg}$, poured onto compacted soil (Berkeley) or directly onto the bedrock (a sandstone at Sheffield). For comparison, the weight of the TEM is around $1,500 \mathrm{~kg}$. Isolation of the base from the ground through the use of, say, airbags was not implemented. It is difficult to state the absolute vibration levels that have been achieved as they vary according to the weather or time of day, but the common observation is that the blocks do attenuate vibrations surprisingly well - by factors of around three in the vertical direction and up to ten in the horizontal directions. Typical amplitudes of vertical vibration in Sheffield were found to be $2.5 \mu$ on the bedrock but less than $1 \mu$ on the concrete base; details at the Berkeley site, measured in $\mu / \mathrm{sec}$, are to be found in [4]. There is further attenuation of vibrations across the microscope support feet.

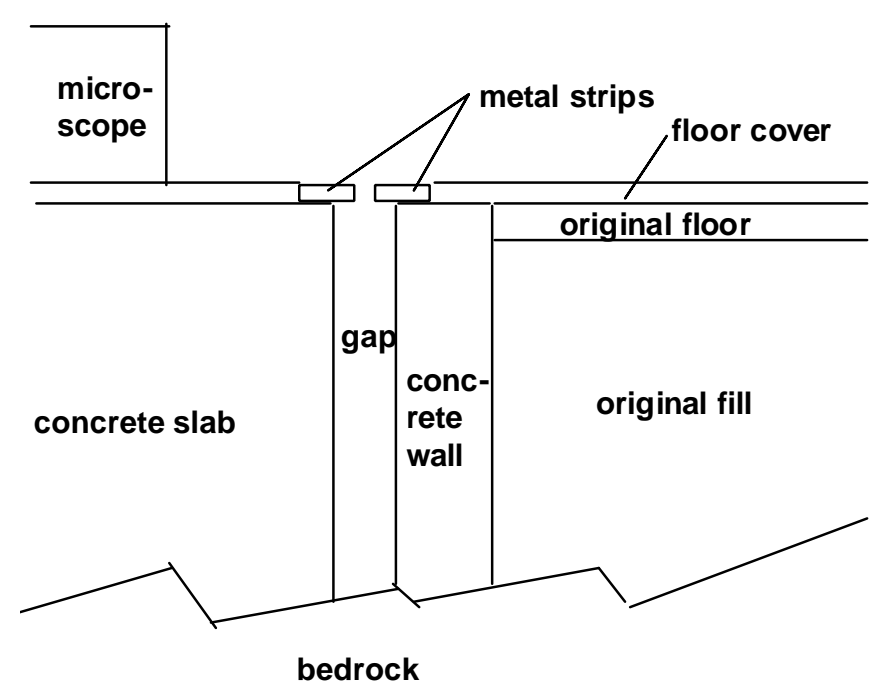

Fig 1. Schematic diagram of the gap separating microscope base from rest of building.
The second possible route for transmission of vibrations into the microscope is movement of the building itself. In addition to locating the microscope on a base independent of the building, it is therefore important to leave a gap between the concrete slab and the floor. Figure 1 shows schematically the arrangement in Sheffield. The two metal strips reduce the 2-cm gap to around $1-2 \mathrm{~mm}$ at floor level. In Berkeley, a 1-inch gap is filled with a closed cell neoprene rubber gasket: the material is not expected to transmit vibrations, and it does prevent solid objects from falling in and bridging the gap.

\section{ACOUSTIC NOISE}

Noise in the room can also lead to vibrations entering the microscope, and the problem is therefore related to that of ground vibrations. The above remarks concerning greater stability requirements of the new microscopes also apply. There are two additional considerations with regard to noise. One is that current high-resolution microscopes tend not to be top entry, but rather side-entry - and any vibrations are more easily transferred to the specimen through the holder. (The increased mass of some recentlydesigned holders has helped attenuate any vibrations.) Secondly, a typical installation now includes additional equipment such as the energy filter and X-ray detector, and the associated computers are sources of noise within the room.

Various precautionary measures are possible both to reduce the entrance of noise and to damp noise in the room. Principal among these is to remove noisy microscope equipment (pumps, power racks, compressor) to another room or into a purpose-built back room (see figure of a room layout later in the text). A small entrance lobby was included in Sheffield and the microscope room is therefore separated from a noisy corridor by two doors. Finally, acoustically "dead" walls may be achieved through curtains or cloth covered fiberglass sound absorbent tiles such as those used in Berkeley, which have a sound absorbent factor of 1.15 .

The line resolution is the ultimate test for the reduction of vibrations through the microscope foundation or from acoustic noise: both machines show details at around $1 \AA$. The tests employed visibility of half fringes using the $\{200\}$ planes in gold (spacing $=1.02 \AA$ ) or diffractograms of amorphous material observed under tilted illumination (the beam being tilted to an angle corresponding to $0.5 \AA^{-1}$ spatial frequency). The term "line resolution" here refers to the finest detail present in an image as opposed to the information resolution which is a measure of the finest detail transferred through the contrast transfer function of the objective lens. 


\section{ELECTROMAGNETIC FIELDS}

Traditionally, the deleterious effect of external fields has been considered only at the specimen/objective lens position, but, on the current TEM's, it may have equal importance at two other locations. Field emission guns have been introduced largely to achieve a probe size of less than $10 \AA$, but external ac fields easily deflect the probe and may render such performance useless. And post-column imaging filters are focused onto the projector lens crossover in the microscope that is located perhaps 1 metre above the filter entrance aperture: so fields located around the viewing and camera chambers become critical too. (The effects of fields around the viewing chamber are also found to be serious in molecular biology applications in which the same low microscope magnifications as used for the imaging filter $-60,000 \mathrm{X}$ or less - are employed to image proteins.)

A reduction of existing fields at the Sheffield site occurred as a result (we presume) of the general overhaul of existing wiring while installing the dedicated supplies for the microscope. The ac fields, once at an unacceptable 2.5 mGauss (rms), are now less than the required 1 mGauss. At the Berkeley site, power conduits were routed as far as possible from the microscope column.

Inside the room, computer monitors are perhaps the biggest source of ac fields. Placement of monitors away from the column is recommended, as is their replacement in the long term by flat-screen monitors, which generate much smaller fields than the conventional monitors.

Field cancellation systems are available. We have found the fields to be reduced to less than $10 \%$ of original value as measured by the sensor belonging to the system, or to around $20 \%$ as measured through an independent loop and oscilloscope. Current systems typically reduce the field at the exact point of the single sensor, but, bearing in mind the importance of fields at the three locations mentioned (specimen, gun, viewing chamber), it is to be hoped that a minimisation of fields along the entire electron optical path in the microscope column will become possible in the future. At present, the systems are more successful at reducing those fields acting on the column that are slowly varying (in space) than those that are varying more rapidly, such as the fields from sources close to the column.

$D C$ and slowly varying fields arise from without the room (movement of trams) and within (movement of a steel chair from microscope to energy filter controls) and these affect the alignment of microscope and imaging filter.

\section{TEMPERATURE FLUCTUATIONS AND AIR FLOW}

Microscopes generate heat, and the ancillary equipment that is found in today's installations generate even more heat: it is therefore essential to cool the installation. Heat-producing equipment (water chiller, power supply) located in a back room may be cooled easily. It is, however, often a problem to cool the microscope room itself without causing an airflow that disturbs the microscope performance or without introducing temperature fluctuations above the prescribed figure (typically $0.5^{\circ} \mathrm{C} / \mathrm{hour}$ )

Various approaches exist. One is to do nothing, except rely on the heat escaping the room through the cooling water and through the walls. A rough estimate of the heat output of a microscope is $5 \mathrm{~kW}$ of which $3 \mathrm{~kW}$ is removed via the cooling water and $2 \mathrm{~kW}$ dissipates into the room. The installation in Sheffield, in the cool month of March, settled at a temperature of $25^{\circ} \mathrm{C}$ in the microscope room when the cooling system for the rear room was set to maintain a temperature in there of $17^{\circ} \mathrm{C}$. Air currents in the microscope room are minimal, and the ventilation for the microscope room, which remains to be installed, will be interrupted as required. A more sophisticated approach would be to line the walls with cooled radiators to extract the heat in a more controlled manner

A more standard approach is to install air-conditioning in the microscope room, which involves blowing in cool air and extracting warm. To avoid unacceptable currents, the inlets might be placed well away from the column, and arranged to produce laminar flow, as in Berkeley. Alternatively, the inlet might take the form of hundreds of small holes across the ceiling (but with none directly above the column). Air cooling systems typically cycle the cooling - switching the incoming air on and off according to the temperature. This cycling must be minimised; one solution is to introduce a large bag to act as a buffer for the incoming air. (In Cambridge, this arrangement also helped reduce the admission of dust into the room.)

Finally, it is worth commenting that the modern TEM, with field emission gun and imaging filter, now tends to be left turned on for extended periods of several months in order to maintain the stability and alignments. Monitors alone are routinely turned off (or put into energy saving mode), if they are not already replaced with the cooler flat-screen models. 


\section{ROOM LAYOUT}

Although the layout will vary between sites, as a consequence of the different equipment to be installed, and the constraints of the particular site, we show in figure 2 a schematic diagram of a hypothetical installation based on the one in Sheffield. The area in front of the column is shown to be $4 \mathrm{~m}$ by $1.5 \mathrm{~m}$ : the actual dimensions in Sheffield are $3.5 \mathrm{~m}$ by $1.2 \mathrm{~m}$, which is satisfactory, but on the small side. Not shown in the figure are the small channels formed in the floor to carry the conduits for the field cancellation cables: the $X$ and $Y$ loops pass directly under the column, up the walls and inside the false ceiling, the $Z$ loop passes around the perimeter of the false ceiling at a height of around $4 \mathrm{~m}$ above the floor. An alternative arrangement (see [4]) is to place the HT tank off the block and in the back room with a corresponding decrease in the size of the block. Channels in the concrete slab and floor were included at the Berkeley site for the cables and plumbing that pass between microscope and back room.

\section{FURTHER COMMENTS}

Post-column imaging filters, such as the Gatan Imaging Filter, now play a valuable rôle in the imaging and analysis of many materials, as they allow inelastically scattered electrons to be removed or selected for the mapping of elements. It should be recognised though, that they do modify significantly the operation of the microscope. The accelerating voltage of the microscope is typically adjusted from, say, $200 \mathrm{kV}$ to $197 \mathrm{kV}$, and the filter introduces a further magnification of between 17x and 38x, depending on the size of the CCD camera in the filter. There are therefore, in effect, two distinct modes of operation of the microscope, depending on whether the final image is located at the microscope viewing screen or camera, or at the imaging filter CCD camera.

The use of a CCD camera makes possible the immediate assessment of an image and its associated diffractogram. (To display satisfactorily a full $1 \mathrm{k}$ by $1 \mathrm{k}$ image, a monitor should be chosen that can display up to 1600 by 1200 resolution.) The improved turn-around of results is considerable, and monitoring the influence of vibrations, noise etc. becomes more straightforward. The diffractograms are not only live but, on a FEG machine, more detailed (more rings visible and a greater focus range) and these factors combine to make the demonstration of HREM theory and contrast transfer functions far more satisfactory. On the other hand, the motivation to learn the theory is put at risk by the implementation of automatic routines for alignment and astigmatism correction.

Provision of the SF6 insulating gas for the HT tank is generally left to the customer, and we record here that use of technical grade $(99.9 \%)$ rather than the electronic grade $(99.999 \%)$ has been found to be satisfactory at Sheffield. The provision of an adequate number of regular power sockets (in addition to the special outlets for the microscope, chiller etc.) is essential. In Sheffield, the microscope room currently has 14 sockets in use, 2 of which supply the extensions for the 8 plugs of the imaging filter, and a further 6 sockets are in use in the back room.

A rough synopsis of the actual timetable for preparing the room and installing the microscope in Sheffield follows not as a guide, but as an indicator of the progress that may or may not be achieved elsewhere.

Month 1: preparation of hole in floor and concrete base

Month 2: prepare ceiling, walls and floor

Month 3: install electrical supplies and lighting

Month 4: decoration, lay floor cover

Month 5: install field cancellation, and air-cooling system in back room

Month 6: microscope delivered and assembled

Month 7: alignments and testing of instrument 


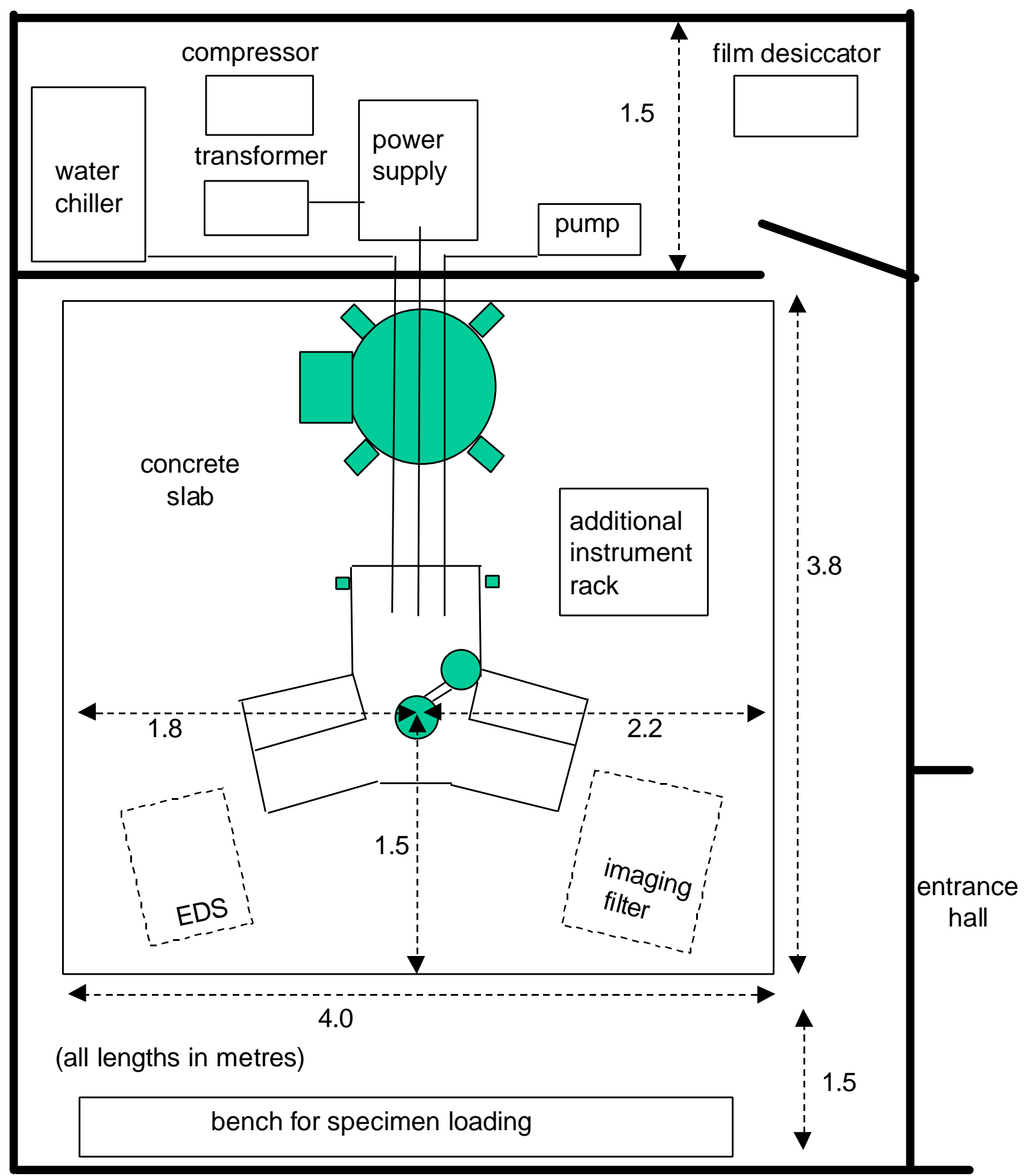

Fig 2. A typical layout of an installation with FEGTEM, energy filter and X-ray analysis. Note dimensions of block and consignment of much equipment to separate room at rear. 


\section{CONCLUSIONS}

The provision of an environment having very low levels of ground vibration, acoustic noise, stray electromagnetic fields and airflow and temperature is essential if the new field emission gun transmission electron microscopes are to achieve full performance. During the course of two installations of these instruments, experience has been gathered on the nature of ground vibrations and their attenuation though the concrete microscope base, on the ac fields that may be present and their cancellation, on the requirements of a satisfactory layout of equipment in the room and on the suppression of air temperature fluctuations and acoustic noise. Satisfactory performance of two FEGTEM's has been achieved at two locations, both purpose built and refitted.

\section{ACKNOWLEDGMENTS}

CJDH, SW and AGC gratefully acknowledge the financial support of the EPSRC (UK) and Prof. C.R. Whitehouse for provision of laboratory facilities. The work of JHT, ECN and MAOK is supported by the Office of Energy Research, Office of Basic Energy Sciences, Materials Sciences Division of the U.S. Department of Energy under Contract No. DE-AC03-76SF00098. P. Lander and M. Pearson of JEOL (UK) Ltd and R. Mueller of Philips (US) Ltd are thanked for their co-operation with the preparation of this manuscript. Useful discussions with others, too numerous to mention, are also acknowledged.

\section{REFERENCES}

1. R.H. Anderson, Design of the Electron Microscope Laboratory, volume 4 of Practical Methods in Electron Microscopy, edited by A.M. Glauert, North-Holland, Amsterdam, 1975.

2. M.A. O'Keefe, Ultramicroscopy 47 (1992) pp282-297.

3. M.A. O'Keefe, Microscopy and Microanalysis, vol. 3, supp. 2, (1997) pp1165-1166.

4. J.H. Turner, M.A. O’Keefe, R. Mueller, Microscopy and Microanalysis, vol. 3, supp. 2, (1997) pp11771178. 